Correspondence

Eva V Varga, Department of Pharmacology, College of

Medicine, University of Arizona, Tucson, AZ 85724, USA. E-mail: evarga@email.arizona.edu

\section{morphine-mediated pain sensitization and} antinociceptive tolerance are blocked by intrathecal treatment with

\section{Keywords}

opioid; Raf-1; hyperalgesia; allodynia; analgesic tolerance; CGRP

\section{Received}

13 November 2009

Revised

19 January 2010

Accepted

25 February 2010

\title{
Raf-1-selective siRNA
}

\author{
S Tumati ${ }^{1}$, WR Roeske ${ }^{1-3}$, T Largent-Milnes ${ }^{1}, \mathrm{R}_{\text {Wang }}{ }^{1}$, TW Vanderah ${ }^{1,4}$ \\ and EV Varga ${ }^{1,3,5}$ \\ ${ }^{1}$ Department of Pharmacology, The University of Arizona, Tucson, AZ, USA, ${ }^{2}$ Department of \\ Medicine, The University of Arizona, Tucson, AZ, USA, ${ }^{3}$ The Sarver Heart Center, The University \\ of Arizona, Tucson, AZ, USA, ${ }^{4}$ Department of Psychiatry, The University of Arizona, Tucson, AZ, \\ USA, and ${ }^{5}$ The BIO5 Institute, The University of Arizona, Tucson, AZ, USA
}

\section{BACKGROUND AND PURPOSE}

Long-term morphine treatment enhances pain neurotransmitter [such as calcitonin gene-related peptide (CGRP)] levels in the spinal cord. It has been suggested previously that increased spinal CGRP may contribute to sustained morphine-mediated paradoxical pain sensitization and antinociceptive tolerance. Previous in vitro studies from our group indicated that Raf-1 kinase-mediated adenylyl cyclase superactivation played a crucial role in sustained morphine-mediated augmentation of basal and evoked CGRP release from cultured primary sensory neurons. The present study was aimed to evaluate the physiological significance of this molecular mechanism in vivo, in rats.

\section{EXPERIMENTAL APPROACH}

Rats were intrathecally (i.th) injected with a Raf-1-selective small interfering RNA (siRNA) mixture for 3 days and were subsequently infused with saline or morphine, s.c. for 7 days. Thermal and mechanical sensory thresholds of the animals were assessed by daily behavioural tests. After final behavioural testing (day 6), spinal cords were isolated from each animal group and spinal CGRP and Raf-1 protein levels were measured using ELISA and immunohistochemistry.

\section{KEY RESULTS}

Selective knockdown of spinal Raf-1 protein levels by i.th Raf-1-selective siRNA pretreatment significantly attenuated sustained morphine-mediated up-regulation of CGRP immunoreactivity in the spinal cord of rats and prevented the development of thermal hyperalgesia, mechanical allodynia and antinociceptive tolerance.

\section{CONCLUSIONS AND IMPLICATIONS}

Raf-1 played a significant role in sustained morphine-mediated paradoxical pain sensitization and antinociceptive tolerance in vivo. These findings suggest novel pharmacological approaches to improve the long-term utility of opioids in the treatment of chronic pain.

\section{Abbreviations}

AC, adenylyl cyclase; CGRP, calcitonin gene-related peptide; DRG, dorsal root ganglion; dsRNA, double-stranded RNA; ELISA, enzyme-linked immunosorbent assay; i.th, intrathecal; PKA, protein kinase A; Raf-1, c-Raf or Raf-1 kinase; siRNA, small interfering RNA 


\section{Introduction}

Opioid medication is commonly used for the clinical treatment of moderate to severe acute and chronic pain (Arner et al., 1988). Prolonged administration of opiates results in the development of analgesic tolerance, wherein over time, higher doses of the drug are required to produce the same degree of analgesia (Arner et al., 1988). Such increased opiate doses are more likely to produce serious side effects and drug addiction (Arner et al., 1988). Sustained opioid exposure was also found to cause a paradoxical pain sensitization that may contribute to the need for opioid dose escalation in order to achieve pain relief (Mao et al., 1995; Vanderah et al., 2000; 2001).

It was shown previously that prolonged opiate administration up-regulates pain neurotransmitter [such as calcitonin gene-related peptide (CGRP)] levels in the primary sensory neurons (Ma et al., 2000) and augments evoked CGRP release in the spinal cord of rats (Gardell et al., 2002). The time course of enhanced spinal CGRP release correlated with the onset of paradoxical pain sensitization and antinociceptive tolerance. The cellular and molecular mechanisms underlying sustained morphine treatment-mediated augmentation of spinal pain neurotransmitter release are currently not entirely clear.

Previous investigations have indicated that in cultured neurons as well as in recombinant model cells, sustained opioid treatment increases the sensitivity of adenylyl cyclase(s) (AC) towards stimulators (AC superactivation) leading to increased intracellular cAMP (cyclic AMP) concentrations (Sharma et al., 1977; Rubenzik et al., 2001; Varga et al., 2003a,b). AC superactivation has been proposed as a putative cellular mechanism of opioid tolerance (Sharma et al., 1977). We hypothesize that - by activation of protein kinase A (PKA) - AC superactivation may play an important role in regulating pain neurotransmitter release from the primary sensory neurons (Figure 1).

Raf- 1 is the most studied kinase in the mitogenactivated protein kinase (MAP kinase) pathway, consisting of Raf-1/MEKK/MAPK (Morrison and Cutler, 1997). Raf-1 kinase also plays a key role in phosphorylation of certain AC isoenzymes (Tan et al., 2001). Previous studies from our laboratory indicated that in recombinant cells stably expressing human opioid receptor types, sustained opioid agonist treatment causes AC superactivation in a Raf-1dependent manner (Varga et al., 2003a,b; Yue et al., 2006; see Figure 1). Our recent in vitro experiments have shown that Raf- 1 also plays a crucial role in sustained morphine-mediated AC superactivation

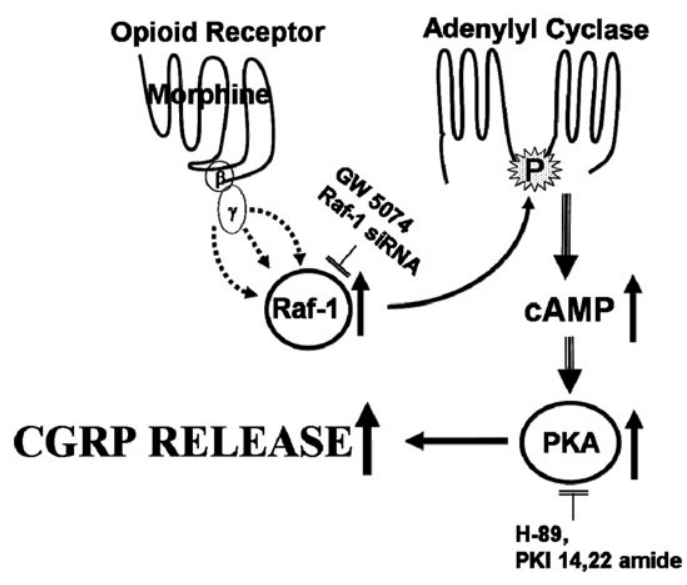

\section{Figure 1}

The putative molecular mechanism of sustained morphine-mediated augmentation of basal and capsaicin-evoked such as calcitonin generelated peptide (CGRP) release from primary sensory neurons. Sustained opioid agonist (such as morphine) treatment causes the phosphorylation of adenylyl cyclase(s) (Varga et al., 1999) in a Raf1-dependent manner (Varga et al., 2003a,b). Raf-1-mediated phosphorylation augments the catalytic activity of adenylyl cyclase(s) (Tan et al., 2001) leading to increased forskolin-stimulated (Malatynska et al., 1996; Rubenzik et al., 2001; Varga et al., 2003a,b; Yue et al., 2008) and basal (Tumati et al., 2009) cAMP formation. In cultured primary sensory neurons increased cellular CAMP formation leads to a cAMP-regulated protein kinase A (PKA)-dependent augmentation of basal (Yue et al., 2008) and capsaicin-evoked (Tumati et al., 2009) CGRP release.

in cultured neonatal rat primary sensory dorsal root ganglion (DRG) neurons (Yue et al., 2008) and that inhibition of either PKA or Raf- 1 activity attenuates sustained morphine-mediated augmentation of both basal (Yue et al., 2008) and evoked (Tumati et al., 2009) CGRP release from cultured neonatal rat primary sensory neurons in vitro.

The aim of the present study was to evaluate the in vivo role of Raf-1 in the development of sustained morphine-mediated paradoxical pain sensitization and antinociceptive tolerance. Our data demonstrated that selective knock-down of spinal Raf-1 protein levels by intrathecal (i.th) Raf-1-selective small interfering RNA (siRNA) pretreatment attenuated the sustained morphine-mediated up-regulation of CGRP immunoreactivity in the spinal cord of rats and prevented the development of thermal hyperalgesia, mechanical allodynia and antinociceptive tolerance in rats.

\section{Methods}

\section{Animals}

Handling, care, maintenance and testing of the animals were performed in accordance with the 
policies and recommendations of the International Association for the Study of Pain and the National Institutes of Health guidelines for the handling and use of laboratory animals. The experimental protocol was approved by the Animal Care and Use Committee of the University of Arizona.

Adult (200-225 g) male Sprague-Dawley rats (Harlan Sprague-Dawley, Indianapolis, IN, USA) were kept in a climate-controlled room on a $12 \mathrm{~h}$ light/dark cycle with food and water available ad libitum.

\section{Intrathecal catheter implantation}

For catheter implantation, the rats (4-6 animals in each treatment group) were anaesthetized by ketamine-xylazine $\left(80 \mathrm{mg} \cdot \mathrm{mL}^{-1}\right.$ ketamine hydrochloride and $20 \mathrm{mg} \cdot \mathrm{mL}^{-1}$ xylazine hydrochloride given at a dose of $1 \mathrm{~mL} \cdot \mathrm{kg}^{-1}$, i.p.) and were implanted with i.th catheters $(8 \mathrm{~cm}$ polyethylene- 10 tubing) so that the catheter terminated in the lumbar region of the spinal cord (Yaksh and Rudy, 1976). The exteriorized end of the catheter was secured by exposing it to a mild flame. The animals were allowed to recover for 7 days before any further experimental manipulations. Animals with signs of motor weakness or paralysis were excluded from further experimentation. Prior to drug treatment, the free flow of fluids through the catheters (patency) was verified by injecting saline solution and the animals were subjected to baseline nociceptive tests as described below. The experimental design for surgery and drug treatment is represented in Figure 2.

\section{Intrathecal siRNA administration}

The rat Raf-1-selective siRNA mixture (Smart pool Dharmacon Inc., Chicago, IL, USA \# L-087699-00) and the control, non-targeting double-stranded RNA (dsRNA) construct (Dharmacon Inc., Chicago, IL, USA \#D-001810-01-20) were reconstituted in double distilled RNAse-free water to a stock concentration of $100 \mu \mathrm{M}$ and stored in aliquots at $-80^{\circ} \mathrm{C}$. On the first day of the experiment aliquots of the dsRNA (Raf-1 siRNA or non-targeting dsRNA) stock solutions were mixed $(1: 5 \mathrm{v} / \mathrm{v})$ with a transfection reagent (i-Fect; Neuromics, Edina, MN, USA) to achieve a final concentration of $2 \mu \mathrm{g}$ per $10 \mu \mathrm{L}$ and were administered to the appropriate rat groups through the i.th catheters, once daily for 3 days, as described by Luo et al. (2005). In the vehicle control group, each rat received $10 \mu \mathrm{L}$ of i-Fect reagent only. i.th dsRNAs or transfection agent injections alone did not cause any overt sign of behavioural toxicity.

\section{Sustained morphine administration}

After 3 days of pretreatment with transfection lipid or Raf-1 siRNA or non-targeting dsRNA, osmotic
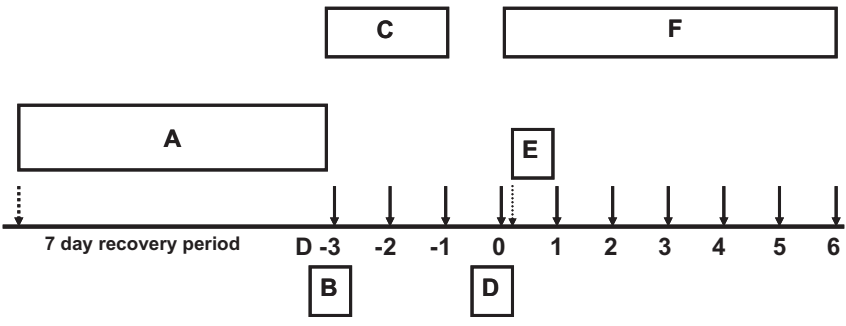

Figure 2

Experimental design. (A) All the rats used for the study were intrathecally catheterized, followed by a 7 day recovery period. (B) On the eighth day, represented as day -3 (D-3), all the animals were assessed for paw withdrawal latencies (Radiant heat test), paw withdrawal thresholds (VonFrey filament test) and tail flick latencies (tail flick test). (C) After assessment, the animals received once-daily injections (intrathecal; i.th) of vehicle (transfection reagent, $10 \mu \mathrm{L}$ ) or Raf-1 siRNA $(2 \mu \mathrm{g}$ per $10 \mu \mathrm{L})$ or non-targeting dsRNA $\left(2 \mu \mathrm{g} \cdot 10^{-1} \cdot \mu \mathrm{L}^{-1}\right)$ for 3 days until day -1 . (D) On day 0 , all the animals were reassessed followed by osmotic minipump implantation into the subcutaneous space close to the thoracic region on the dorsal side. Saline $\left(1 \mu \mathrm{L} \cdot \mathrm{h}^{-1}\right)$ or morphine $\left(45 \mathrm{nmol} \cdot \mu \mathrm{L}^{-1} \cdot \mathrm{h}^{-1}\right)$ was delivered for 7 days through the minipumps. (E) All of the animals were checked for paw withdrawal latency and threshold $6 \mathrm{~h}$ (one-fourth day) after saline or morphine pump implantation. Acute antinociception was measured after 6 h. (F) From day 1 to day 6 , the animals received vehicle or Raf-1 siRNA or non-targeting dsRNA every other day as described in Figure 3. Paw withdrawal latencies and thresholds, tail flick latencies were measured once daily. Finally, on day 6 , the animals were challenged with three doses of morphine $(1,3$, $10 \mu \mathrm{g}$ per $10 \mu \mathrm{L}$ ), and acute nociception was recorded using tail flick test. The remaining animals were killed either for measurement of calcitonin gene-related peptide content in their spinal cords or for immunohistochemistry experiments.

minipumps (Alza, Mountain view, CA, USA) were implanted into the subcutaneous space by making a $1 \mathrm{~cm}$ incision on the dorsal surface of the skin. The minipumps were pushed deep into the skin such that they are closer to the thoracic region in each rat for sustained delivery of morphine $\left(45 \mathrm{nmol} \cdot \mu \mathrm{L}^{-1} \cdot \mathrm{h}^{-1}\right)$ or saline $\left(1 \mu \mathrm{L} \cdot \mathrm{h}^{-1}\right)$ for 7 days. The above concentration of morphine was selected as per Gardell et al. (2002) and Vanderah et al. (2000). Alternate day treatments with the appropriate siRNA or transfection lipid continued throughout sustained morphine treatment (see Figure 2).

\section{Behavioural tests}

Thermal hyperalgesia. The method of Hargreaves et al. (1988) was used to assess the sensitivity of rats to a mildly noxious thermal stimulus, as previously described (Gardell et al., 2002). Briefly, the animals were placed in a plexi-glass container equipped with a wire-mesh floor and a radiant heat source was focused onto the plantar surface of their hind-paw. Paw withdrawal latencies were measured using a motion detector, before (baseline), during and after sustained drug (morphine or saline) administration 
Table 1

Experimental animal groups in the study

\begin{tabular}{|c|c|}
\hline Experimental animal group & Explanation \\
\hline Naive & Animals were not subjected to surgery or any drug intervention \\
\hline Vehicle-pretreated + saline (control) & $\begin{array}{l}\text { Animals received vehicle (transfection reagent, } 10 \mu \mathrm{L} \text { ) intrathecally once daily for } 3 \text { subsequent } \\
\text { days, then implanted with saline osmotic minipumps s.c. delivering saline at } 1 \mu \mathrm{L} \cdot \mathrm{h}^{-1} \text { for } 7 \text { days } \\
\text { during which vehicle is given every other day }\end{array}$ \\
\hline Raf-1 siRNA + saline & $\begin{array}{l}\text { Animals received Raf- } 1 \text { siRNA ( } 2 \mu \mathrm{g} \text { per } 10 \mu \mathrm{L} \text { ) intrathecally once daily for } 3 \text { subsequent days, then } \\
\text { implanted with saline osmotic minipumps s.c. delivering saline at } 1 \mu \mathrm{L} \cdot \mathrm{h}^{-1} \text { for } 7 \text { days during } \\
\text { which Raf- } 1 \text { siRNA is given every other day }\end{array}$ \\
\hline Non-targeting dsRNA + saline & $\begin{array}{l}\text { Animals received non-targeting dsRNA }(2 \mu \mathrm{g} \text { per } 10 \mu \mathrm{L}) \text { intrathecally once daily for } 3 \text { subsequent } \\
\text { days, then implanted with saline osmotic minipumps s.c. delivering saline at } 1 \mu \mathrm{L} \cdot \mathrm{h}^{-1} \text { for } 7 \text { days } \\
\text { during which non-targeting dsRNA is given every other day }\end{array}$ \\
\hline Vehicle-pretreated + morphine & $\begin{array}{l}\text { Animals received vehicle (transfection reagent, } 10 \mu \mathrm{L} \text { ) intrathecally once daily for } 3 \text { subsequent } \\
\text { days, then implanted with morphine osmotic minipumps s.c. delivering morphine at } \\
45 \mathrm{nmol} \cdot \mu \mathrm{L}^{-1} \cdot \mathrm{h}^{-1} \text { for } 7 \text { days during which vehicle is given every other day }\end{array}$ \\
\hline Raf-1 siRNA + morphine & $\begin{array}{l}\text { Animals received Raf- } 1 \text { siRNA ( } 2 \mu \mathrm{g} \text { per } 10 \mu \mathrm{L} \text { ) intrathecally once daily for } 3 \text { subsequent days, then } \\
\text { implanted with morphine osmotic minipumps s.c. delivering morphine at } 45 \mathrm{nmol} \cdot \mu \mathrm{L}^{-1} \cdot \mathrm{h}^{-1} \text { for } 7 \\
\text { days during which Raf- } 1 \text { siRNA is given every other day }\end{array}$ \\
\hline Non-targeting dsRNA + morphine & $\begin{array}{l}\text { Animals received non-targeting dsRNA ( } 2 \mu \mathrm{g} \text { per } 10 \mu \mathrm{L} \text { ) intrathecally once daily for } 3 \text { subsequent } \\
\text { days, then implanted with morphine osmotic minipumps s.c. delivering morphine at } \\
45 \mathrm{nmol} \cdot \mu \mathrm{L}^{-1} \cdot \mathrm{h}^{-1} \text { for } 7 \text { days during which non-targeting dsRNA is given every other day }\end{array}$ \\
\hline
\end{tabular}

(see Figure 2). A maximal cut-off of $33 \mathrm{~s}$ was used to prevent tissue damage. All the treatment groups were indicated in Table 1 . Six individual animals were included in each treatment group.

Mechanical allodynia. Paw withdrawal threshold in response to mild, normally innocuous tactile stimuli were determined by probing with von Frey filaments (0.4-15.1 gm), as previously described (Vanderah et al., 2000). The filaments were applied perpendicularly to the plantar surface of the right hind-paw of the rats. Paw withdrawal thresholds were measured by sequentially increasing and then decreasing the stimulus strength ('up-and-down' method). The data were analysed using the Dixon non-parametric test (Dixon, 1980; Chaplan et al., 1994). All the treatment groups were indicated in Table 1. Six individual animals were included in each treatment group.

Antinociceptive tolerance. Nociceptive testing was performed by placing the distal third of the tail of the rats in a $52^{\circ} \mathrm{C}$ water bath, as described previously (Vanderah et al., 2000). The latency of tailwithdrawal was measured with an accuracy of $0.1 \mathrm{~s}$. A cut-off time of $10 \mathrm{~s}$ was used to prevent tissue injury. Morphine (1, 3 and $10 \mu \mathrm{g}$ per $5 \mu \mathrm{L})$ doseantinociceptive response curves were measured for the rats before (naïve) and after siRNA or vehicle pretreatment and sustained (6 days) of morphine or saline (control) infusion. The applied morphine doses were selected based on the previous investigations of Vanderah et al. (2000). Data were converted to percent of maximal possible effect (MPE) to generate dose-response curves by the following formula: (response latency - baseline latency)/(cutoff - baseline latency) $\times 100$. The animals were considered tolerant if they exhibited significant $(P<$ $0.05)$ reduction in their tail-withdrawal latency in response to the morphine dose ( $10 \mu \mathrm{g}$ per $\left.5 \mu \mathrm{L}^{1}\right)$ that produced $90 \%$ of the MPE in the naïve animals $\left(A_{90}\right)$. The tolerant animals would show a considerable rightward shift in the acute $(30 \mathrm{~min})$ morphine dose-antinociceptive response. The $\mathrm{A}_{90}$ dose was calculated in all the treatment groups by extrapolation of the dose-response curves. All the treatment groups were indicated in Table 1. Five individual animals were included under each treatment group.

\section{Spinal cord extraction and tissue preparations} After behavioural tests, the animals were deeply anaesthetized with halothane and killed by decapitation. The spinal columns were cut through at the pelvic girdle and were hydraulically extruded with ice-cold saline by inserting a 16-gauge needle into the sacral vertebral canal. The spinal tissues were placed on ice and the dorsal halves of the lumbar areas were dissected. The tissue samples were immediately frozen in liquid nitrogen and stored at $-80^{\circ} \mathrm{C}$ until the time of the assays. 
Measurement of spinal Raf-1 protein level

Frozen spinal cord tissues were thawed and placed in a homogenization buffer $[20 \mathrm{mM}$ Tris, $4 \mathrm{mM}$ EDTA, 2 mM EGTA, 1\% protease inhibitor cocktail (Sigma, St. Louis, MO, USA), pH 8.0] and homogenized on ice with a polytron homogenizer. After centrifugation $\left(10000 \times g, 30 \mathrm{~min}, 4^{\circ} \mathrm{C}\right)$, the supernatants were collected and boiled in reducing SDS sample buffer (Invitrogen, Carlsbad, CA, USA) for 5 min. Total protein concentrations were determined in each sample by the Bradford assay (Bradford, 1976), using serial bovine serum albumin solutions as standards. Sample aliquots containing $10 \mu \mathrm{g}$ total soluble protein were resolved on $10 \%$ SDS-polyacrylamide gels (NuPAGE, Invitrogen, Carlsbad, CA, USA) and transferred to nitrocellulose membranes. Raf-1 protein level was detected by incubating with a rabbit Raf-1-specific primary antibody (1:1000, Millipore, Billerica, MA, USA) and a horseradish peroxidase-conjugated goat antirabbit secondary antibody (1:100 000, Santa Cruz Biotechnology Inc., Santa Cruz, CA, USA). As an internal control, we also performed Western blots for each sample using a primary antibody against the 'housekeeping' protein, $\beta$-actin (1:10 000, Santa Cruz Biotechnology Inc., Santa Cruz, CA, USA) and a horseradish peroxidase-conjugated goat anti-rabbit secondary antibody (1:100 000, Santa Cruz Biotechnology). Immunoreactive bands were detected using the SuperSignal West Dura chemiluminescent detection kit (Pierce Technology, Thermo Scientific, Rockford, IL, USA). The intensities of the Raf-1 immunoreactive bands were normalized for the ODs of the control $\beta$-actin bands in each sample. Optical densities of the chemiluminescent bands were determined using the Image J software (NIH). Spinal cords from each treatment group have been included in this study, and four individual animals were included per treatment group.

\section{Measurement of spinal CGRP concentration}

Spinal cord tissues were thawed and homogenized in homogenization buffer as described in the previous section. After centrifugation $(10000 \times g, 30 \mathrm{~min}$, $4^{\circ} \mathrm{C}$ ), the supernatants were collected and total protein concentrations were determined by the Bradford method. A CGRP enzyme immunoassay kit (Cayman Chemicals, Ann Arbor, MI, USA) containing an antibody specific for rat CGRP (1-17) was used to measure CGRP concentrations in the supernatants. Standard curves were constructed using synthetic CGRP solutions. CGRP content was calculated using the Graph Pad Prism 4.0 software (San Diego, CA, USA).

\section{Immunohistochemistry}

Immunohistochemistry was performed by a protocol modified from Gardell et al. (2002). Briefly, after behavioural testing, the rats were anaesthetized with intraperitoneal ketamine-xylazine $\left(100 \mathrm{mg} \cdot \mathrm{kg}^{-1}\right)$ injections and transcardially perfused with 0.1 M phosphate-buffered saline (PBS) ( $\mathrm{pH} 7.4)$ until the exudate ran clear and then with $10 \%$ formalin for 15 min. Lumbar (L) spinal cords were harvested. The tissues were fixed in 10\% formalin solution overnight and cryoprotected with 20\% sucrose in $0.1 \mathrm{M}$ PBS. The fixed tissues were saturated with $30 \%$ sucrose in $0.1 \mathrm{M}$ PBS solution and embedded in Tissue-Tek Optimal Cutting Temperature Compound (Sakura, Torrance, CA, USA) and sliced in a cryostat at $-20^{\circ} \mathrm{C}$. Serial spinal cord sections $(20 \mu \mathrm{m}$ each) were placed onto slides so that each slide contained an ordered series from the lumbar spinal cord. The mounted lumbar spinal cord sections were extensively rinsed and blocked in $0.1 \mathrm{M}$ PBS containing 10\% goat serum, for $2 \mathrm{~h}$, at room temperature. The sections were incubated with a guinea pig anti-CGRP antiserum (1:40 000; Peninsula Laboratories, Belmont, CA, USA) in 0.1 M PBS containing 2\% goat serum and $0.3 \%$ Triton $\mathrm{X}-100$ overnight at $4^{\circ} \mathrm{C}$, followed by washing and incubation (2 h) with an Alexa Fluor 594conjugated goat anti-guinea pig secondary antibody (1:1000; Molecular Probes, Eugene, OR, USA). After immunoreactions, the sections were rinsed and mounted in the Vectashield (Vector Laboratories, Burlingame, CA, USA) mounting medium. Fluorescence images were digitally captured using a Nikon (Tokyo, Japan) E800 fluorescence microscope, equipped with the appropriate standard filters. Images were acquired and analysed using a Hamamatsu C5810 colour CCD camera and its proprietary Image Processor Software (Hamamatsu, Bridgewater, NJ, USA). The acquired images were processed using Adobe PhotoShop (Adobe Systems, San Jose, CA, USA).

\section{Data analysis}

Thermal and tactile hypersensitivity data were analysed by two-way repeated measures ANOVA and/or two-way ANOVA (post hoc, Newman-Keuls) while, the measurement of CGRP content data and antinociceptive tolerance data were analysed by non-parametric one-way ANOVA (post hoc, NewmanKeuls) using the GraphPad Prism 4.0 software. A non-parametric repeated measure one-way ANOVA (post hoc, Newman-Keuls) was also performed to compare the baselines with the entire time course within each treatment group (within-subjects comparison for variation over time). Statistical differences were considered significant at $P<0.05\left({ }^{*} P<\right.$ 
A

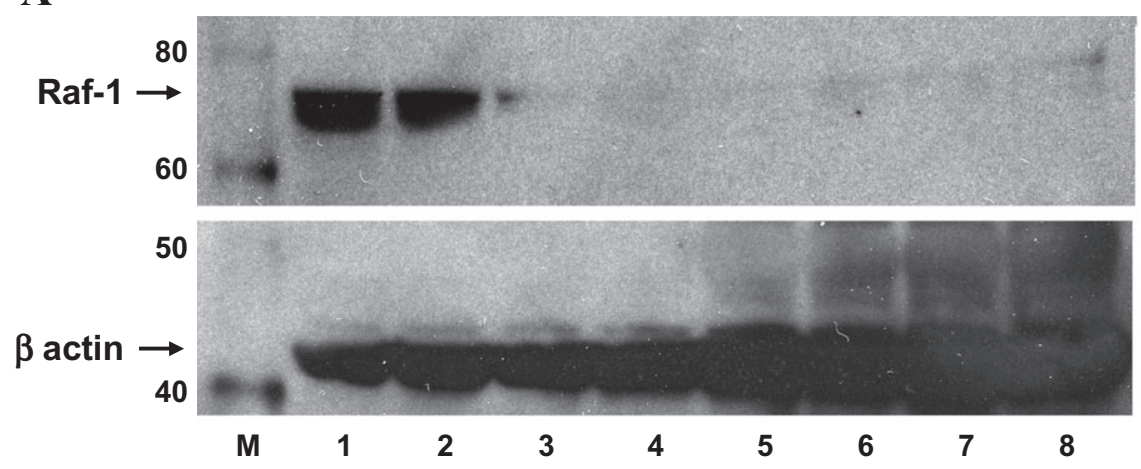

B

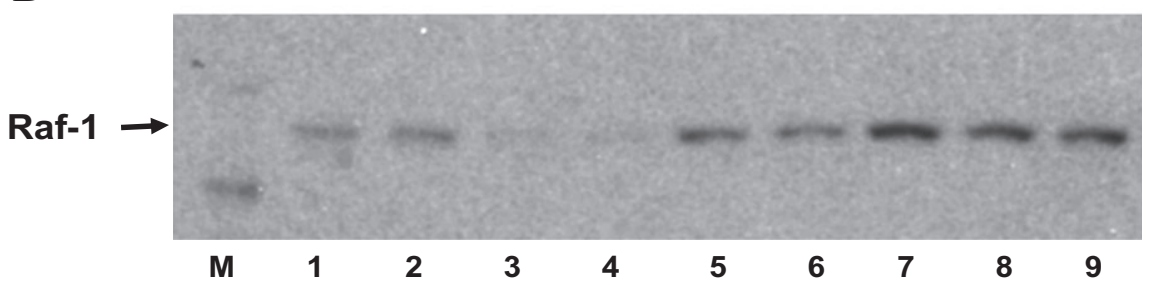

\section{Figure 3}

(A) Intrathecal Raf-1-selective siRNA pretreatment reduces Raf-1 protein levels in rat lumbar spinal cord homogenates. Male Sprague-Dawley rats received intrathecal (i.th) injections of transfection reagent (lanes 1-2), $2 \mu \mathrm{g}$ per $10 \mu \mathrm{L}$ Raf-1-specific siRNA once (lanes 3-5) or twice (a total of $4 \mu \mathrm{g}$ per day, lanes 6-8) daily for 3 days. After i.th siRNA pretreatment for respective number of days, lumbar spinal cord sections were harvested and homogenized. The lumbar spinal cord homogenates from each rat were loaded on $8 \%$ SDS-polyacrylamide gel and Western blots were performed with primary antibodies against Raf- 1 and $\beta$-actin. $\beta$-Actin is used as a loading control (see Methods). Lane M: molecular weight markers. (B) Recovery of Raf-1 protein levels in rat lumbar spinal cord homogenates after 3 days of i.th Raf- 1 siRNA administration. Male Sprague-Dawley rats received i.th injection of $2 \mu \mathrm{g}$ per $10 \mu \mathrm{L}^{-1}$ Raf-1-specific siRNA once daily on days 1, 2 and 3 (lanes 1-3). Starting from day 4 , the Raf-1 levels were allowed to recover until day 9 (lanes 3-9). After i.th pretreatment, lumbar spinal cord homogenates from each rat were loaded on 8\% SDS-polyacrylamide gel and Western blot was performed with primary antibody against Raf-1. Lane M: molecular weight markers. Hence, we decided to administer Raf-1 siRNA every other day to maintain the knock-down levels of Raf-1. Each lane represents the protein loaded from each animal. A total of three animals were used per group.

$0.05,{ }^{* *} P<0.01$ and $\left.{ }^{* *} P<0.001\right)$. Data were represented as mean \pm SEM, unless otherwise indicated.

\section{Materials}

Ketamine hydrochloride and xylazine hydrochloride were from Sigma-Aldrich, St. Louis, MO, USA; halothane from Associated Medical Supply, Scottsdale, AZ, USA and morphine from the National Institute on Drug Abuse, Bethesda, Maryland, USA. Receptor and ion channel nomenclature used in this manuscript follows Alexander et al. (2009).

\section{Results}

Intrathecal Raf-1-selective siRNA treatment significantly reduces Raf-1 protein level in the lumbar spinal cord of rats

After vehicle or siRNA pretreatments (see Figure 2), each group of rats was implanted with a subcutane- ous minipump for continuous drug (saline or morphine) delivery. This procedure caused no behavioural abnormalities (ataxia, catatonia, loss of righting, or placement response) in the animals under study.

Treatment groups used were explained in detail in Table 1. Raf-1 protein level in the lumbar spinal cords of naïve, animals pretreated with vehicle, Raf1-selective siRNA mixture or non-targeting dsRNA was assessed by Western blots. A total of three independent animals per each group were used in this study. In lumbar spinal cord extracts from naïve rats, the Raf-1-selective antibody recognized a diffuse band in the molecular weight range of 72-74 kDa (Figure 3A, lanes 1 and 2). i.th Raf-1selective siRNA pretreatment significantly reduced Raf-1 protein levels in the lumbar spinal cord tissue homogenates (Figure 3A, lanes 3-8). Quantitative analyses of the immunoreactive bands (Raf-1 immunoreactive bands vs. the respective $\beta$-actin protein 
bands) indicate that i.th pretreatment with $2 \mu \mathrm{g}$ dose of Raf-1-selective siRNA, once daily for 3 days reduced Raf-1 protein levels to $90 \pm 7 \%$ relative to naïve control (Figure 3A, lanes 3-5). Because i.th pretreatment with a larger siRNA dose ( $4 \mu \mathrm{g}$ per day; 3 days) did not cause any further reduction in spinal Raf-1 protein levels (Figure 3A, lanes 6-8), we selected the $2 \mu \mathrm{g}$ dose for Raf-1-selective siRNA treatment for further experiments.

In order to determine the time schedule for Raf-1 siRNA treatment, we also determined the time course of spinal Raf- 1 recovery after the cessation of the siRNA pretreatment. Animals were treated with Raf-1-selective siRNA every day until a significant reduction in the Raf-1 protein levels was noticed (3 days) and then Raf- 1 protein levels were allowed to recover by stopping the Raf-1 siRNA administration. Raf- 1 levels in the lumbar spinal cord were monitored using Western blots for a period of 9 days (Figure 3B). Our experiments indicated that Raf-1 protein levels remained at reduced levels for 2 days after the cessation of the siRNA pretreatment but started to recover from the third day (Figure 3B). Thus, in order to maintain reduced Raf-1 protein levels, in further experiments a maintainence dose $(2 \mu \mathrm{g})$ Raf-1 siRNA was given i.th every other day throughout the entire experimental protocol.

\section{Intrathecal administration of Raf-1-selective SiRNA attenuates sustained} morphine-mediated augmentation of CGRP immunoreactivity in the dorsal horn of the lumbar spinal cord

Calcitonin gene-related peptide concentration in lumbar spinal cord dorsal horn homogenates was measured by enzyme immunoassay. Basal CGRP content in the lumbar dorsal horn tissue of vehicle saline-infused rats was $1470 \pm 260 \mathrm{pg} \cdot(\mathrm{mg}$ protein $)^{-1}$. As shown in Figure 4, sustained (6 days) morphine treatment augmented CGRP content by $125 \%(P<0.01$ relative to saline control group, one-way ANOVA, $n=4$ ). i.th pretreatment with a Raf-1-selective siRNA mixture significantly attenuated sustained (6 days) morphine-mediated augmentation of CGRP immunoreactivity in the dorsal horn of the lumbar spinal cord $(P>0.05$ relative to the vehicle-pretreated saline group, oneway ANOVA, $n=4$ ) (Figure 4 ). The CGRP content in animals pretreated with the non-targeting dsRNA and receiving saline was similar to the basal CGRP value in the vehicle-pretreated saline-infused animals ( $P>0.05$, one-way ANOVA, $n=4)$. The CGRP content in animals pretreated with the nontargeting dsRNA and receiving morphine was similar to the vehicle-pretreated morphine-infused

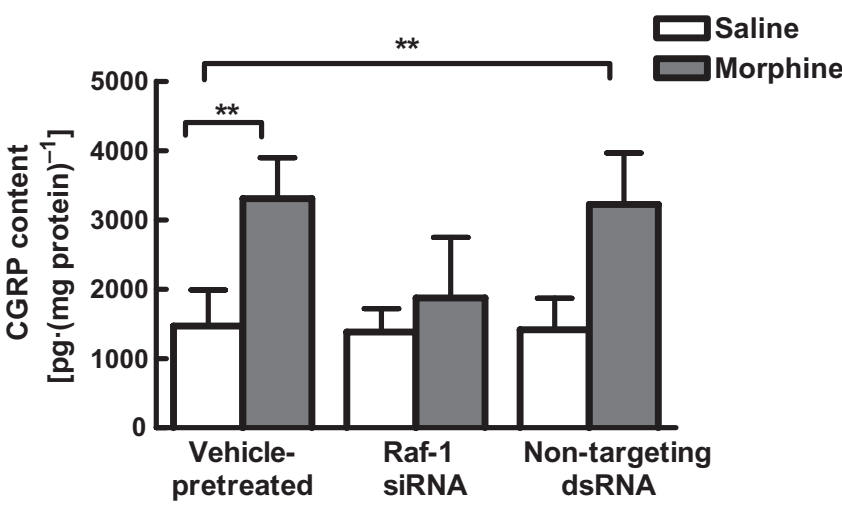

Figure 4

Intrathecal Raf-1-selective siRNA pretreatment attenuates sustained morphine-mediated augmentation of calcitonin gene-related peptide (CGRP) levels in lumbar spinal cord homogenates of rats. Male Sprague-Dawley rats were subcutaneously implanted with osmotic minipumps delivering sustained saline or $45 \mathrm{nmol} \cdot \mu \mathrm{L}^{-1} \cdot \mathrm{h}^{-1}$ morphine infusion for 7 days. CGRP content in the supernatants of lumbar dorsal horn homogenates was measured using a rat CGRP EIA kit (Cayman Chemicals) (see Methods). Sustained morphine treatment significantly augmented CGRP concentration in the lumbar dorsal horn of rats $\left({ }^{* *} P<0.01\right.$ relative to the vehicle saline-infused group; one-way ANOVA; $n=4$ ). Interestingly, pretreatment with the Raf-1-selective siRNA significantly reduced sustained morphinemediated up-regulation of CGRP content $(P>0.05$ relative to vehicle saline-infused group; one-way ANOVA; $n=4)$. Results from rats pretreated with non-targeting dsRNA were similar to those from vehiclepretreated rats indicating that the effects of Raf- 1 siRNA are specific (refer to Results section).

animals $(P<0.01$ relative to vehicle-pretreated saline group, one-way ANOVA, $n=4$ ) indicating that the effects mediated by Raf- 1 siRNA were specific (Figure 4).

We also performed immunofluorescence histochemistry in lumbar spinal cord slices to confirm our data. CGRP-like immunoreactivity in the lumbar spinal cord of saline-treated rats was chiefly apparent in the outer laminae (laminae I-II). Sustained morphine treatment greatly increased immunofluorescence intensities in these areas and also extended immunolabelling into the deeper laminae (Figure 5). i.th pretreatment of the rats with a Rafselective siRNA mixture attenuated the effect of sustained morphine treatment on CGRP-like immunoreactivity in the lumbar spinal cord slices (Figure 5). The figure is a representative of similar immunohistochemistry data obtained from three independent animals. In summary, data from the immunofluorescence histochemistry and CGRP enzyme immunoassay are in good correlation with each other and demonstrate the role of Raf- 1 in regulation of pain neurotransmitter synthesis and/or release in the dorsal horn of the lumbar spinal cord of rats. 

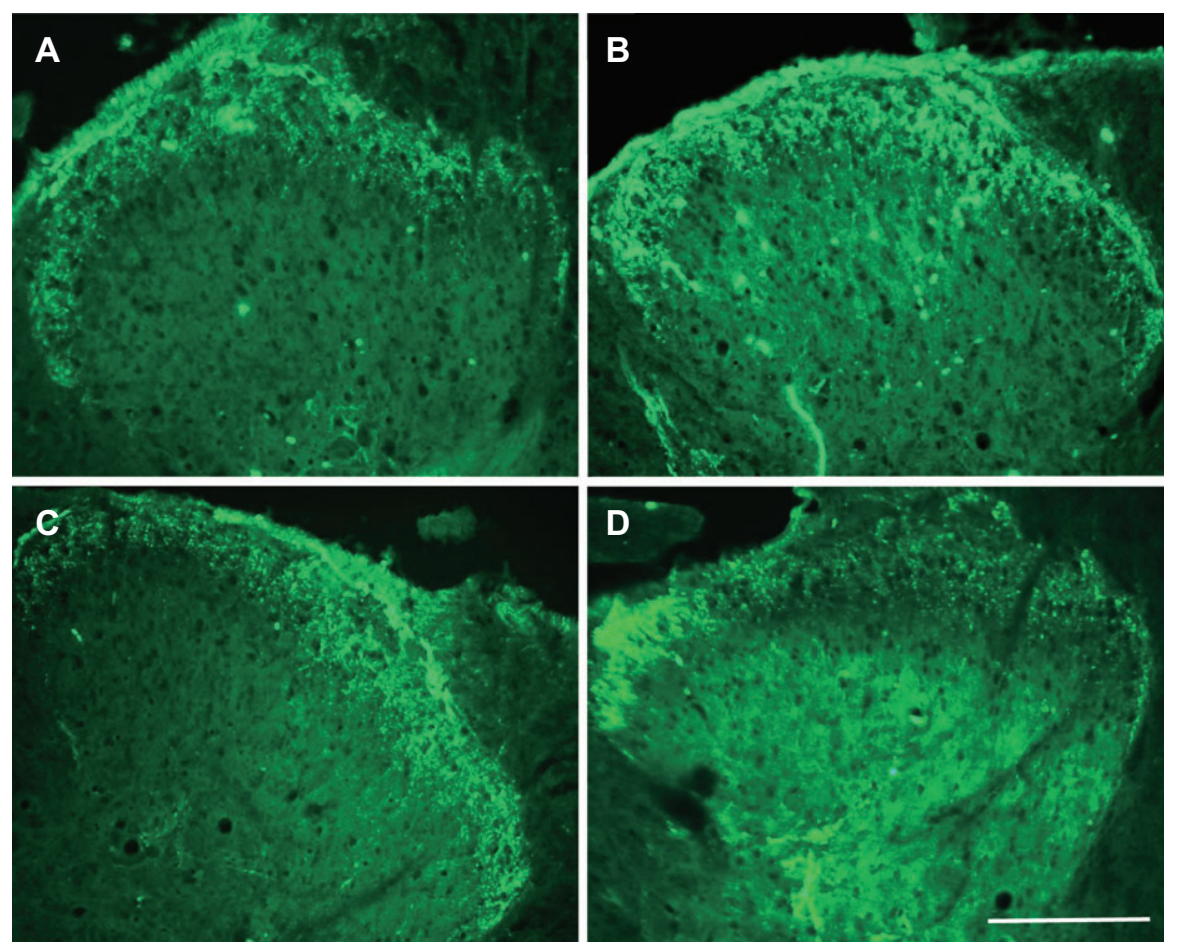

\section{Figure 5}

Intrathecal (i.th) Raf-1-selective siRNA treatment attenuates sustained morphine-mediated augmentation of calcitonin gene-related peptide (CGRP) immunoreactivity in the lumbar spinal cord of rats. Male Sprague-Dawley rats received i.th vehicle (A, B) or Raf-1-selective siRNA (C, D) treatments for 3 days (see Figure 3). After pretreatment, each animal group was divided into two subgroups and received sustained subcutaneous saline $(A, C)$ or morphine $\left(45 \mathrm{nmol} \cdot \mu \mathrm{L}^{-1} \cdot \mathrm{h}^{-1}\right)$ infusion $(B, D)$ for 7 days. Lumbar spinal cord slices were incubated with an anti-CGRP primary antibody followed by a fluorescent-labelled secondary antibody (Alexa Fluor 594-conjugated goat anti-rabbit secondary antibody). Immunofluorescent images were collected using a Nikon E800 fluorescence microscope. Scale bar represents $100 \mu \mathrm{m}$. Three animals were used for the immunohistochemical analysis.

\begin{abstract}
Sustained morphine-induced thermal hypersensitivity is blocked by intrathecal Raf-1-selective siRNA pretreatment Intrathecal catheter implantation caused no significant change in the sensitivity of the animals towards mildly noxious heat stimulus (baseline paw withdrawal latencies were similar to the preinfusion baseline $(P>0.05, n=6)$ (Figure 6). i.th pretreatments with either the vehicle (21.2 $\pm 0.4 \mathrm{~s})$, non-targeting dsRNA or the Raf-1-selective siRNA alone did not alter response thresholds in rats receiving sustained saline infusions for 7 days $(P>$ 0.05 relative to pre-infusion baseline, two-way ANOVA, $n=6$ ). Paw withdrawal latencies remained similar in the above groups throughout the 7 day time period $(P>0.05$ within each group, one-way repeated measures ANOVA, $n=6$ ) (Figure 6).
\end{abstract}

Acute $(6 \mathrm{~h})$ morphine $\left(45 \mathrm{nmol} \cdot \mu \mathrm{L}^{-1} \cdot \mathrm{h}^{-1}\right)$ administration significantly increased radiant heat paw withdrawal latencies in vehicle-pretreated rats $(P<$ 0.01 relative to the pre-infusion baseline, one-way repeated measures ANOVA, $n=6$ ). Raf-1-selective siRNA or non-targeting dsRNA pretreatment had no effect on the acute antinociceptive effectiveness of morphine $(P<0.01$ in each group relative to the vehicle saline-infused group, one-way repeated measures ANOVA, $n=6$ ) (Figure 6). Sustained morphine administration led to a progressive decline in the apparent antinociceptive effect of morphine in vehicle and in non-targeting dsRNA-pretreated animals $(P<0.05$ in each group relative to paw withdrawal latency in the vehicle saline-infused group, two-way ANOVA, $n=6$ ) (Figure 6). Finally, longer ( $>2$ days) sustained s.c. morphine infusion led to a gradual development of thermal hypersensitivity in vehicle and non-targeting dsRNApretreated animals $(P<0.05$ within each group, oneway repeated measures ANOVA, $n=6$ ). Thermal hyperalgesia in these animals was detectable after 3 days of morphine treatment (Figure 6) and reached maximal level $(P<0.01$ relative to the vehicle salineinfused group, two-way ANOVA) on day 6 of morphine infusion. These data indicate that i.th treatment with dsRNA did not have non-specific effects on the nociceptive reflexes of the rats (Figure 6). 


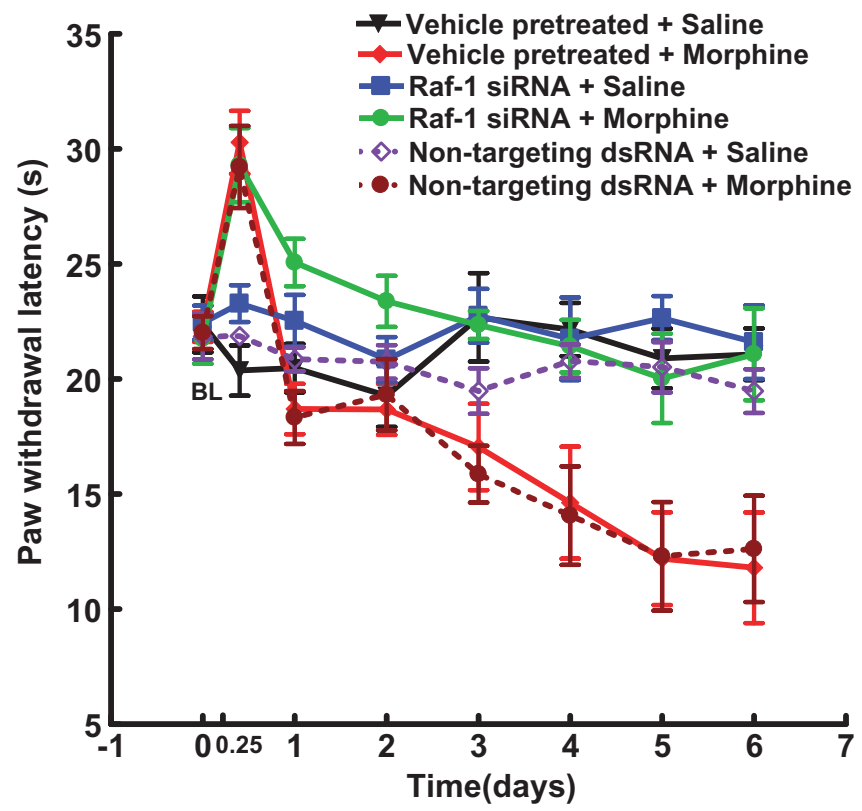

Figure 6

Intrathecal Raf-1-selective siRNA treatment attenuates sustained morphine-mediated thermal hyperalgesia. The groups of rats included in the study were explained in Table 1. Paw withdrawal latencies in response to radiant heat applied to the plantar surface of the hind-paw of all the experimental groups of rats were determined $6 \mathrm{~h}$ after osmotic minipump implantation and once daily during the 7 days of morphine (or saline) treatment. siRNA treatment continued on alternate days during morphine infusion. Acute ( $6 \mathrm{~h}$ or 0.25 day) morphine treatment produced a $50 \%$ increase in paw withdrawal latencies in all the groups that received morphine. Thermal hypersensitivity was significant $(P<0.05$ relative to vehicle + saline group $21.2 \pm 0.4 \mathrm{~s}$; two-way ANOVA, $n=6$ ) in vehicle-pretreated and non-targeting dsRNA-pretreated animals receiving morphine infusion. Intrathecal pretreatment with the Raf-1-selective siRNA on the other hand significantly attenuated sustained morphine-mediated thermal hyperalgesia even after 6 days of sustained morphine treatment $(P>0.05$ relative to vehicle + saline group; two-way ANOVA, $n$ $=6$ ). Six animals were included in each treatment group. BL, baseline values.

Interestingly, i.th pretreatment of the rats with the Raf-1-selective siRNA mixture completely blocked the development of thermal hypersensitivity upon sustained morphine treatment. Thus, paw withdrawal latencies in the Raf-1 siRNA-pretreated animals were not significantly different from the baseline even after 6 days of sustained morphine infusion $(P>0.05$ relative to that of the vehicle saline-infused group, two-way ANOVA, $n=6$ ).

\section{Intrathecal Raf-1-selective siRNA treatment blocks sustained morphine-induced mechanical allodynia}

Sustained administration of morphine by subcutaneous infusion through an osmotic pump $\left(45 \mathrm{nmol} \cdot \mu \mathrm{L}^{-1} \cdot \mathrm{h}^{-1}\right)$ produced tactile allodynia in

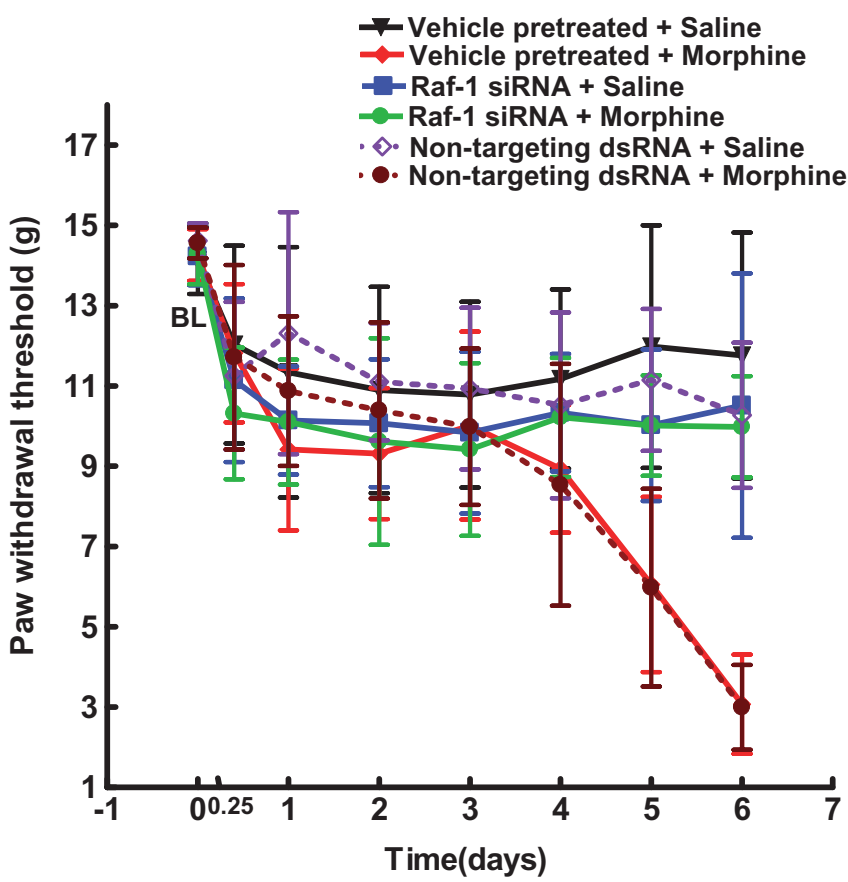

Figure 7

Intrathecal Raf-1-selective siRNA pretreatment attenuates sustained morphine-mediated tactile allodynia. For description of the animal groups see Table 1. Paw withdrawal thresholds in response to a series of von Frey filaments applied to the plantar surface of the hind-paw of all the experimental groups of rats were determined $6 \mathrm{~h}$ after osmotic minipump implantation and once daily during the 7 days of morphine (or saline) treatment. siRNA treatment was continued on alternative days during morphine infusion (see Methods). Acute (6 h or 0.25 day) morphine treatment however did not produce any significant difference in paw withdrawal latencies relative to the saline-infused animals. Tactile hypersensitivity was significant $(P<$ 0.05 for the entire curve, relative to vehicle + saline group; two-way ANOVA, $n=6$ ) in vehicle-pretreated and non-targeting dsRNApretreated animals receiving sustained morphine infusion. Intrathecal pretreatment with the Raf-1-selective siRNA on the other hand significantly attenuated sustained morphine-mediated tactile hypersensitivity even after 6 days of sustained morphine treatment $(P>$ 0.05 relative to vehicle + saline group; two-way ANOVA, $n=6$ ). Six animals were included in each treatment group. BL, baseline values.

vehicle-pretreated rats. Baseline paw withdrawal thresholds were similar to the pre-infusion baseline $(P>0.05)$ (Figure 7). i.th pretreatments with either the vehicle, non-targeting dsRNA or the Raf-1selective siRNA alone did not alter response thresholds in rats receiving sustained saline infusions for 7 days $(P>0.05$ relative to pre-infusion baseline, twoway ANOVA). In addition, the paw withdrawal thresholds remained similar within the above groups throughout the 7 day time period $(P>0.05$ within each group, one-way repeated measures ANOVA, $n=6$ ) (Figure 7).

Acute $(6 \mathrm{~h})$ morphine $\left(45 \mathrm{nmol} \cdot \mu \mathrm{L}^{-1} \cdot \mathrm{h}^{-1}\right)$ administration did not cause any significant increase in paw withdrawal thresholds in either treatment 
groups $(P>0.05$ relative to the pre-infusion baseline, one-way repeated measures ANOVA, $n=6$ ) (Figure 7). Sustained morphine administration led to a decline in the paw withdrawal thresholds of vehiclepretreated animals and non-targeting dsRNApretreated animals after 5 days of sustained morphine infusion (Figure 7). Thus, on day 6 of continued morphine infusion, paw withdrawal threshold in the von Frey filament test was significantly lower than that in vehicle saline-infused animals $(P<0.01$, two-way ANOvA, $n=6)$ (Figure 7$)$.

Intrathecal administration of Raf-1-selective siRNA $(2 \mu$ g per $10 \mu \mathrm{L})$ did not produce a significant alteration in baseline response threshold even on day 6 of saline infusion $(P>0.05$, relative to the vehicle-pretreated saline-infused group, two-way ANOVA, $n=6$ ). However, i.th Raf-1-selective siRNA pretreatment significantly attenuated the development of tactile allodynia after 6 days of sustained morphine treatment $(P<0.05$ relative to the vehiclepretreated morphine-infused group, two-way ANOVA, $n=6$ ). i.th administration of a non-targeting dsRNA and saline infusion did not produce a significant alteration in the response threshold to nonnoxious mechanical stimulation on day $6(P>0.05$ relative to the vehicle-pretreated saline-infused group, two-way ANOVA, $n=6$ ). Furthermore, in the non-targeting dsRNA-treated group, sustained morphine treatment produced tactile allodynia on day 6 similar to the vehicle-pretreated saline group $(P<$ 0.01 relative to vehicle-pretreated saline-infused group, two-way ANOVA, $n=6$ ).

\section{Intrathecal Raf-1-selective siRNA treatment blocks the development of antinociceptive tolerance}

Acute morphine dose-nociceptive response curves were measured in naïve rats and after sustained systemic morphine or saline infusions in vehicle, Raf-1 siRNA and non-targeting dsRNA-pretreated rats using the $52^{\circ} \mathrm{C}$ water tail flick test. Acute i.th morphine injections $(1 \mu \mathrm{g}$ per $5 \mu \mathrm{L}, 3 \mu \mathrm{g}$ per $5 \mu \mathrm{L}$ and $10 \mu \mathrm{g}$ per $5 \mu \mathrm{L}$ ) produced antinociception in a dosedependent manner with the same $A_{90}$ value in naïve as in the vehicle-pretreated saline-infused animals (Figure 8). The $A_{90}$ dose was used to evaluate antinociceptive effectiveness of morphine in vehiclepretreated and Raf-1 siRNA-pretreated animals that received sustained morphine infusion. Sustained (7 days) systemic morphine $\left(45 \mathrm{nmol} \cdot \mu \mathrm{L}^{-1} \cdot \mathrm{h}^{-1}\right)$ infusion caused a rightward shift in the dose-response curve in the vehicle-pretreated animals, so that the naive $A_{90}$ dose produced only $20 \pm 1 \%$ of the MPE. Upon extrapolation of the results, the dose that produces $\mathrm{A}_{90}$ response in this group was found to be

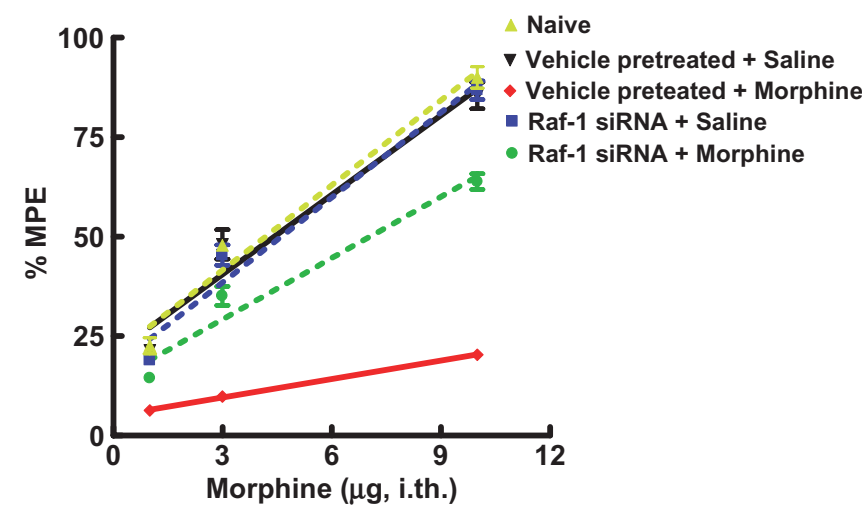

\section{Figure 8}

Intrathecal (i.th) Raf-1-selective siRNA pretreatment attenuates sustained morphine-mediated antinociceptive tolerance. The groups of animals have been described in detail in Table 1. After sustained morphine (or saline) treatment, on day 6 the animals were challenged with acute $(30 \mathrm{~min})$ morphine doses and antinociceptive dose-nociceptive response curves were measured using the $52^{\circ} \mathrm{C}$ hot water tail flick test. Antinociceptive tolerance is indicated by a significant rightward shift in the dose-response curves and by a significant reduction in the \% antinociceptive effect after receiving the naïve $A_{90}$ dose $\left(10 \mu \mathrm{g} \cdot \mathrm{kg}^{-1}\right)$ of morphine. $A_{90}$ dose was calculated for the morphine-infused group by extrapolation of the respective doseresponse curve (refer to Results section). A total of five animals per treatment group were included in this study. MPE, maximal possible effect.

$55 \pm 2.5 \mu \mathrm{g}$ indicating the development of antinociceptive tolerance (Figure 8).

Intrathecal pretreatment of Raf-1-selective siRNA had no effect on the antinociceptive efficacy of acute i.th morphine in saline-infused animals (87 \pm $2 \%$ of MPE at the naive $A_{90}$ dose) (Figure 8). The dose that produces $A_{90}$ response in the Raf- 1 siRNA + saline group was found to be similar to the $A_{90}$ dose in naïve animals. Interestingly however, the i.th Raf1-selective siRNA pretreatment greatly attenuated sustained morphine-mediated rightward shift in the acute i.th morphine dose-response curve. Thus, re-challenge with the naive $A_{90}$ dose $(10 \mu$ g per $5 \mu \mathrm{L})$ produced $64 \pm 2 \%$ antinociception in the Raf-1selective siRNA-pretreated rats $\left({ }^{* *} P<0.01\right.$ relative to vehicle-pretreated morphine-infused rats, one-way ANOVA, $n=5$ ) with the A $A_{90}$ dose obtained by extrapolation of the dose-response curve. Thus, i.th pretreatment with Raf- 1 siRNA significantly attenuated the development of antinociceptive tolerance in the morphine-infused group (Figure 8).

\section{Discussion and conclusions}

The results of the present study demonstrate that knock-down of Raf-1 protein levels in the lumbar spinal cord of rats by i.th Raf-1-selective siRNA 
pretreatment significantly attenuates the development of sustained morphine-mediated thermal hyperalgesia, tactile allodynia and antinociceptive tolerance. In addition, our studies show that i.th Raf-1-selective siRNA treatment also attenuates sustained morphine-mediated augmentation of CGRPlike immunoreactivity in the lumbar spinal cord. Taken together, these data suggest that spinal Raf- 1 may have an important role in the development of sustained morphine-mediated paradoxical pain sensitization and antinociceptive tolerance in vivo.

It has been well demonstrated that acute opioids inhibit pain transmission. On the other hand, longterm opioid treatment frequently causes a paradoxical pain sensitization in the form of hyperalgesia and allodynia (Vanderah et al., 2000) and increases spinal pain neurotransmitter (such as CGRP, substance $\mathrm{P}$ and glutamate) content in rodents (Menard et al., 1996; Powell et al., 2000; Gardell et al., 2002; 2006) and in cultured primary sensory neurons (Ma et al., 2000; 2001; Yue et al., 2008). Several studies indicate that sensitization of pain neurotransmitter release from the primary sensory DRG neurons (peripheral sensitization) might be a crucial event in the development of antinociceptive tolerance (Kolesnikov et al., 1996; Stein et al., 2009), but the underlying mechanisms are still unclear. We expect that further understanding of the molecular mechanism of sustained opioid analgesic-mediated intracellular adaptations in the primary sensory neurons may aid in the identification of the initial step that triggers further downstream neural system-wise adaptations.

In the present work we demonstrated that sustained morphine-mediated thermal hyperalgesia, tactile allodynia, antinociceptive tolerance and augmentation of CGRP-like immunoreactivity in the lumbar spinal cord of rats is attenuated by knockdown of spinal Raf-1 protein levels. The most studied physiological role of Raf- 1 is the activation of the MAP kinase pathway (Morrison and Cutler, 1997). It is well established that acute opioids, such as morphine activate the Raf-1/MEKK/MAPK signal transduction cascade in recombinant cell lines (Gutstein et al., 1997) as well as in cultured primary sensory neurons (Ma et al., 2001). Morphinemediated activation of the MAPK pathway is generally transient and desensitizes within minutes after receptor stimulation. Interestingly however, it was found previously that in small and medium sized DRG neurons long-term (6 days) morphine exposure markedly increases activated pERK immunoreactivity, while it does not change total ERK levels (Ma et al., 2001). Shorter (1-4 day) morphine treatment caused no increase in phosphoERK immunoreactivity. Consequently, it is possible that in vivo, in the sensory neurons presently uncharacterized cellular adaptations counteract the desensitization of the Raf-1/MAPK pathway. Possible cellular adaptation mechanisms include a translocation of the $\mu$-opioid receptor signalling complex into a different cellular compartment (Bayewitch et al., 2000; Zhao et al., 2006) or/and changes in the concentration/ activity of intracellular regulators (Eisinger and Ammer, 2009). Thus, previous evidence suggests that long-term morphine treatment may lead to a sustained activation of the Raf-1/MEKK/MAPK pathway in primary sensory neurons.

Sustained morphine-mediated activation of Raf- 1 may augment CGRP synthesis and/or may promote CGRP release in primary sensory neurons by at least two different molecular mechanisms. Activation of p42/44 MAP kinases may regulate CGRP gene transcription in the sensory neurons. Indeed, previous data show that inhibition of the p42/44 MAPK pathway downstream of Raf-1 (using the MEK inhibitor, PD98059) attenuates sustained morphinemediated augmentation of CGRP content in the dorsal horn and in primary sensory neurons (Trang et al., 2005).

The regulation of the p42/44 MAPK pathway however may not be the only (possibly not even the most important) physiological role of Raf- 1 (Galabova-Kovacs et al., 2006). Thus, it was found previously that Raf- 1 also directly phosphorylates several AC isoenzymes increasing their sensitivity to excitatory modulators (AC superactivation) (Tan et al., 2001). Sustained opioid treatment also leads to phosphorylation and superactivation of AC in recombinant cell lines (Sharma et al., 1975; 1977; Avidor-Reiss et al., 1997; Rubenzik et al., 2001; Varga et al., 2003a,b). Both sustained morphine-mediated AC superactivation (Bayewitch et al., 2000; Zhao et al., 2006) and MAPK pathway activation (Zheng et al., 2008) can be attenuated by disruption of lipid rafts.

Sustained morphine treatment also leads to AC superactivation and cAMP overshoot in cultured primary sensory neurons (Yue et al., 2006). Because previous data (Vasko, 1995; Richardson and Vasko, 2002) indicate that intracellular cAMP concentrations regulate CGRP release from cultured primary sensory neurons, earlier we hypothesized that sustained morphine-mediated Raf- 1 activation and the resulting AC superactivation may be the underlying cause of augmented CGRP release from these cells. Indeed, inhibition of Raf-1 activity in vitro in cultured primary sensory neurons significantly attenuated sustained morphine-mediated AC superactivation (Yue et al., 2008), while inhibition of either Raf-1 or PKA prevented sustained morphinemediated augmentation of basal (Yue et al., 2008) 
and capsaicin-evoked (Tumati et al., 2009) CGRP release from cultured neonatal rat DRG neurons in vitro. Although the above study looks at the involvement of Raf- 1 in CGRP release, there is a possibility that other neurotransmitter (such as glutamate, substance P) pathways are also regulated by Raf- 1 upon sustained morphine administration.

In the present work we investigated the hypothesis that prevention of sustained morphinemediated AC superactivation in vivo, by a selective knockdown of Raf-1 protein levels in the dorsal horn of the lumbar spinal cord of rats will prevent the development of sustained morphine-mediated thermal hyperalgesia, tactile allodynia and antinociceptive tolerance. We chose selective siRNA pretreatment for in vivo knock-down of spinal Raf-1 levels because this method provides higher selectivity than the previously used chemical inhibitors. Our data indicate that sustained systemic morphine infusion to control (vehicle-treated) rats for $>3$ days caused thermal hyperalgesia, tactile allodynia and shifted acute morphine antinociceptive doseantinociceptive to the right (analgesic tolerance) in agreement with the data reported in Vanderah et al. (2000) and Tumati et al. (2008). i.th pretreatment of the rats with a Raf-1-selective siRNA mixture on the other hand prevented the development of thermal hyperalgesia, tactile allodynia as well as sustained morphine-mediated shift in the dose-response curve of acute morphine. In our study, the reason that knock-down of Raf-1 protein levels did not completely attenuate sustained morphinemediated, antinociceptive tolerance may represent the involvement of changes at the receptor level, such as dimerizations, desensitization and phosphorylation, in this process. Importantly however, Raf1-selective siRNA pretreatment had no effect on the ability of morphine to produce antinociception upon acute treatment, indicating that i.th Raf-1selective siRNA does not affect the normal sensory thresholds. The effects of the siRNA treatment were presumably selective to Raf- 1 , because i.th pretreatment of the animals with a control, non-targeting dsRNA had no effect on pain sensitivity in either saline- or morphine-infused rats.

In summary, our previous investigations have shown that Raf-1-mediated AC superactivation plays an important role in regulation of CGRP release from cultured primary sensory DRG neurons in vitro, while data from the current investigation demonstrates that this molecular mechanism also plays an important physiological role in vivo, in the development of thermal hyperalgesia, tactile allodynia and antinociceptive tolerance upon sustained morphine treatment of rats. Based on the current experimental data we expect that co-administration of opioid analgesics with a Raf-1 inhibitor may prove to be a useful strategy to prevent paradoxical pain sensitization and antinociceptive tolerance in the treatment of chronic pain.

\section{Acknowledgements}

This work was supported by grants from the National Institutes of Health (Grants DA 06284, GM 065465).

\section{Conflict of interest}

None to declare.

\section{References}

Alexander SPH, Mathie A, Peters JA (2009). Guide to Receptors and Channels (GRAC), 4th edn. Br J Pharmacol 158 (Suppl. 1): S1-S254.

Arner S, Rawal N, Gustafsson LL (1988). Clinical experience of long-term treatment with epidural and intrathecal opioids-a nationwide survey. Acta Anaesthesiol Scand 32: 253-259.

Avidor-Reiss T, Nevo I, Saya D, Bayewitz M, Vogel Z (1997). Opiate-induced adenylyl cyclase superactivation is isoenzyme-specific. J Biol Chem 272: 5040-5047.

Bayewitch ML, Nevo I, Avidor-Reiss T, Levy R, Simonds WF, Vogel Z (2000). Alterations in detergent solubility of heterotrimeric $G$ proteins after chronic activation of $\mathrm{G}(\mathrm{i} / \mathrm{o})$-coupled receptors: changes in detergent solubility are in correlation with onset of adenylyl cyclase superactivation. Mol Pharmacol 57: 820-825.

Bradford MM (1976). A rapid and sensitive method for the quantitation of microgram quantities of protein utilizing the principle of protein-dye binding. Anal Biochem 7: 248-254.

Chaplan SR, Bach FW, Pogrel JW, Chung JM, Yaksh TL (1994). Quantitative assessment of tactile allodynia in the rat paw. J Neurosci Methods 53: 55-63.

Dixon WJ (1980). Efficient analysis of experimental observations. Annu Rev Pharmacol Toxicol 20: 441-462.

Eisinger DA, Ammer H (2009). Down-regulation of c-Cbl by morphine accounts for persistent ERK1/2 signaling in delta-opioid receptor expressing HEK293 cells. J Biol Chem 284: 34819-34828.

Galabova-Kovacs G, Kolbus A, Matzen D, Meissl K, Piazzolla D, Rubiolo C et al. (2006). ERK and beyond: insights from B-Raf and Raf-1 conditional knockouts. Cell Cycle 5: 1514-1518. 
Gardell LR, Wang R, Burgess SE, Ossipov MH, Vanderah TW, Malan TP et al. (2002). Sustained morphine exposure induces a spinal dynorphin-dependent enhancement of excitatory transmitter release from primary afferent fibers. J Neurosci 22: 6747-6755.

Gardell LR, King T, Ossipov MH, Rice KC, Lai J, Vanderah TW et al. (2006). Opioid receptor-mediated hyperalgesia and antinociceptive tolerance induced by sustained opiate delivery. Neurosci Lett 396: 44-49.

Gutstein HB, Rubie EA, Mansour A, Akil H, Woodgett JR (1997). Opioid effects on mitogen-activated protein kinase signalling cascades. Anesthesiology 87: 1118-1126.

Hargreaves K, Dubner R, Brown F, Flores C, Joris J (1988). A new and sensitive method for measuring thermal nociception in cutaneous hyperalgesia. Pain 32: 77-88.

Kolesnikov YA, Jain S, Wilson R, Pasternak GW (1996). Peripheral morphine analgesia: synergy with central sites and a target of morphine tolerance. J Pharmacol Exp Ther 279: 502-506.

Luo MC, Zhang DQ, Ma SW, Huang YY, Shuster SJ, Porreca F et al. (2005). An efficient intrathecal delivery of small interfering RNA to the spinal cord and peripheral neurons. Mol Pain 28: 1-29.

Ma W, Zheng WH, Kar S, Quirion R (2000). Morphine treatment induced calcitonin gene-related peptide and substance P increases in cultured dorsal root ganglion neurons. Neuroscience 99: 529-539.

Ma W, Zheng WH, Powell K, Jhamandas K, Quirion R (2001). Chronic morphine exposure increases the phosphorylation of MAP kinases and the transcription factor CREB in dorsal root ganglion neurons: an in vitro and in vivo study. Eur J Neurosci 14: 1091-1104.

Malatynska E, Wang Y, Knapp RJ, Waite S, Calderon S, Rice K et al. (1996). Human delta opioid receptor: functional studies on stably transfected Chinese hamster ovary cells after acute and chronic treatment with the selective nonpeptidic agonist SNC-80. J Pharmacol Exp Ther 278: 1083-1089.

Mao J, Price DD, Mayer DJ (1995). Mechanisms of hyperalgesia and morphine tolerance: a current view of their possible interactions. Pain 62: 259-274.

Menard DP, van Rossum D, Kar S, St Pierre S, Sutak M, Jhamandas K et al. (1996). A calcitonin gene related peptide receptor antagonist prevents the development of tolerance to spinal morphine analgesia. J Neurosci 16: 2342-2351.

Morrison DK, Cutler RE (1997). The complexity of Raf-1 regulation. Curr Opin Cell Biol 9: 174-179.

Powell KJ, Ma W, Sutak M, Doods H, Quirion R, Jhamandas K (2000). Blockade and reversal of spinal morphine tolerance by peptide and non-peptide calcitonin gene-related peptide receptor antagonists. Br J Pharmacol 131: 875-884.
Richardson JD, Vasko MR (2002). Cellular mechanisms of neurogenic inflammation. J Pharmacol Exp Ther 302: 839-845.

Rubenzik M, Varga E, Stropova D, Roeske WR, Yamamura HI (2001). Expression of alpha-transducin in Chinese hamster ovary cells stably transfected with the human delta-opioid receptor attenuates chronic opioid agonist-induced adenylyl cyclase superactivation. Mol Pharmacol 60: 1076-1082.

Sharma SK, Klee WA, Nirenberg M (1975). Dual regulation of adenylyl cyclase accounts for narcotic dependence and tolerance. Proc Natl Acad Sci USA 72: 3092-3096.

Sharma SK, Klee WA, Nirenberg M (1977).

Opiate-dependent modulation of adenylate cyclase. Proc Natl Acad Sci USA 74: 3365-3369.

Stein C, Clark JD, Oh U, Vasko MR, Wilcox GL, Overland AC et al. (2009). Peripheral mechanisms of pain and analgesia. Brain Res Rev 60: 1-24.

Tan CM, Kelvin DJ, Litchfield DW, Ferguson SSG, Feldman RD (2001). Tyrosine kinase-mediated serine phosphorylation of adenylyl cyclase. Biochemistry 40: 1702-1709.

Trang T, Quirion R, Jhamandas K (2005). The spinal basis of opioid tolerance and physical dependence: Involvement of calcitonin gene-related peptide, substance $\mathrm{P}$ and arachidonic acid-derived metabolites. Peptides 26: 1346-1355.

Tumati S, Largent-Milnes T, Yamamura HI, Vanderah TW, Roeske WR, Varga EV (2008). Intrathecal Raf-1-selective siRNA attenuates sustained morphine-mediated thermal hyperalgesia. Eur J Pharmacol 601: 207-208.

Tumati S, Yamamura HI, Vanderah TW, Roeske WR, Varga EV (2009). Sustained morphine treatment augments capsaicin evoked CGRP release in a PKA and Raf-1 dependent manner. J Pharmacol Exp Ther 330: 810-817.

Vanderah TW, Gardell LR, Burgess SE, Ibrahim M, Dogrul A, Zhong CM et al. (2000). Dynorphin promotes abnormal pain and spinal opioid antinociceptive tolerance. J Neurosci 20: 7074-7079.

Vanderah TW, Suenaga NM, Ossipov MH, Malan TP Jr, Lai J, Porreca F (2001). Tonic descending facilitation from the rostral ventromedial medulla mediates opioid-induced abnormal pain and antinociceptive tolerance. J Neurosci 21: 279-286.

Varga EV, Stropova D, Rubenzik M, Waite S, Roeske WR, Yamamura HI (1999). Phosphorylation of adenylyl cyclase VI upon chronic delta-opioid receptor stimulation. Eur J Pharmacol 364: R1-R3.

Varga EV, Rubenzik MK, Stropova D, Sugiyama M, Grife V, Hruby VJ et al. (2003a). Converging protein kinase pathways mediate adenylyl cyclase superactivation upon chronic $\delta$-opioid agonist treatment. J Pharmacol Exp Ther 306: 109-115. 
Varga EV, Yamamura HI, Rubenzik MK, Stropova D, Navratilova E, Roeske WR (2003b). Molecular mechanisms of excitatory signaling upon chronic opioid agonist treatment. Life Sci 74: 299-311.

Vasko MR (1995). Prostaglandin-induced neuropeptide release from spinal cord. Prog Brain Res 104: 367-380.

Yaksh TL, Rudy TA (1976). Chronic catheterization of the spinal subarachnoid space. Physiol Behav 17: 1031-1036.

Yue X, Varga EV, Stropova D, Vanderah TW, Yamamura HI, Roeske WR (2006). Chronic morphine-mediated adenylyl cyclase superactivation is attenuated by the Raf-1 inhibitor, GW5074. Eur J Pharmacol 540: 57-59.
Yue X, Tumati S, Navratilova E, Stropova D, St John PA, Roeske WR et al. (2008). Sustained morphine treatment augments basal CGRP release from cultured primary sensory neurons in a Raf-1 dependent manner. Eur J Pharmacol 584: 272-277.

Zhao H, Loh HH, Law PY (2006). Adenylyl cyclase superactivation induced by long-term treatment with opioid agonist is dependent on receptor localized within lipid rafts and is independent of receptor internalization. Mol Pharmacol 69: 1421-1432.

Zheng H, Chu J, Qiu Y, Loh HH, Law P-Y (2008). Agonist-selective signalling is determined by the receptor location within the membrane domains. Proc Natl Acad Sci USA 105: 9421-9426. 